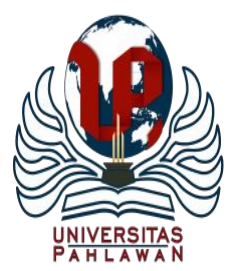

Jurnal Abdidas Volume 2 Nomor 1 Tahun 2021 Halaman 105-113

JURNAL ABDIDAS

http://abdidas.org/index.php/abdidas

\title{
Pemanfaatan Sampah Daun dan Bunga Basah menjadi Kerajinan Ecoprinting
}

\author{
Rezkiyana Hikmah $^{1}$, Ria Asep Sumarni ${ }^{2}$ \\ Program Studi Teknik Informatika, Universitas Indraprasta PGRI Jakarta ${ }^{1,2}$ \\ E-mail : rezkiyana.hikmah2706@gmail.com ${ }^{1}$, riaasepsumarni@gmail.com²
}

\begin{abstract}
Abstrak
Kegiatan pelatihan ecoprinting dilatarbelakangi oleh persoalan kebersihan lingkungan dari sampah dedauanan dan bunga serta ketidaktahuan peserta dalam mengolah sampah tersebut menjadi sesuatu yang bermanfaat. Oleh karena itu, kegiatan pelatihan ecoprinting ini dilaksanakan dengan tujuan untuk menyelesaikan persoalan tersebut. Jumlah peserta kegiatan pelatihan ecoprinting adalah 15 orang peserta ibu-ibu PKK di Pamulang Park Residence. Kegiatan ini terdiri dari tiga tahap yaitu persiapan, pelaksanaan, dan evaluasi. Metode yang digunakan dalam kegiatan pelatihan ecoprinting adalah memberikan demo bagaimana cara mengola sampah dedaunan dan bunga yang basah menjadi produk yang bernilai dan bermanfaat. Saat pelaksanaan peserta dibagi menjadi tiga kelompok yang terdiri dari lima orang peserta. Hal tersebut bertujuan untuk memberikan pengalaman langsung kepada peserta dalam mengolah sampah dedaunan dan bunga menjadi sebuah produk yang bermanfaat. Bahan dan alat yang diperlukan adalah daun atau bunga, kain katun, tawas, cuka, air, baskom, dan palu. Dari hasil kegiatan ini menjadikan Ibu-Ibu PKK di Perumahan Pamulang Park Residence memiliki ketrampilan dalam membuat ecoprinting, yang hasilnya dapat mereka aplikasikan dalam membuat suatu bentuk kerajinan, salah satunya totebag. Selain itu kegiatan ini juga memberikan wawasan kepada warga untuk lebih menjaga lingkungan agar tidak membakar sampah.
\end{abstract}

Kata kunci: pelatihan, kerajinan, ecoprinting, sampah daun

\section{Abstract}

The ecoprinting training activity was motivated by the issue of environmental cleanliness from leaves and flowers and the ignorance of the participants in processing this waste into something useful. Therefore, this ecoprinting training activity was carried out with the aim of solving these problems. The number of participants in the ecoprinting training activity is 15 participants from PKK mothers at Pamulang Park Residence. This activity consists of three stages, namely preparation, implementation and evaluation. The method used in the ecoprinting training activity is to provide a demonstration of how to process wet leaf and flower waste into valuable and useful products. During the implementation the participants were divided into three groups consisting of five participants. It aims to provide participants with direct experience in processing leaf and flower waste into a useful product. The materials and tools needed are leaves or flowers, cotton cloth, alum, vinegar, water, a bowl, and a hammer. From the results of this activity, PKK mothers in Pamulang Park Residence Housing have skills in making ecoprinting, which they can apply in making a form of handicraft, one of which is totebag. In addition, this activity also provides insight to residents to better protect the environment so as not to burn garbage.

Keywords: training, crafts, ecoprinting, leaf litter

Copyright (c) 2021 Rezkiyana Hikmah, Ria Asep Sumarni

$\triangle$ Corresponding author

Address : Universitas Indraprasta PGRI Jakarta

ISSN 2721- 9224 (Media Cetak)

Email : riaasepsumarni@gmail.com

ISSN 2721- 9216 (Media Online)

DOI : https://doi.org/10.31004/abdidas.v2i1.225 
106 Pemanfaatan Sampah Daun dan Bunga Basah menjadi Kerajinan Ecoprinting - Rezkiyana Hikmah, Ria Asep Sumarni

DOI: https://doi.org/10.31004/abdidas.v2i1.225

\section{PENDAHULUAN}

Salah satu kondisi yang dapat diamati dengan jelas di sekitaran tempat tinggal adalah adanya pohon rindang dan tanaman bunga dengan aneka warna. Di depan rumah atau di sepanjang jalan di kompleks perumahan, pasti terdapat banyak pohon dan bunga dengan beraneka ragam bentuk dan warna. Namun keteduhan dan kesejukan suasana lingkungan akan menjadi masalah saat memasuki musim-musim, dimana banyak angin berhembus. Angin-angin yang berhembus kencang akan mengakibatkan banyaknya sampah-sampah daun dan bunga yang berguguran di lingkungan. Sampah-sampah yang tidak disapu akan menjadi kering dan kemudian akan tertiup kembali oleh angin. Hal tersebut membuat lingkungan semakin kotor.

Mengatasi masalah ini, biasanya orangorang akan mengumpulkan sampah-sampah daun kering tersebut untuk kemudian dibakar dan menjadi abu begitu saja. Kebiasaan membakar sampah masih mendarah daging di masyarakat dusun dalam menangani permasalahan sampah (Taufiq \& Maulana, 2015). Selain dengan membakar, mengatasi sampah juga dilakukan dengan cara mengubur atau membuangnya ke saluran air atau sungai (Pohan \& Supriharjo, 2013). Orang-orang menganggap cara ini merupakan cara yang efektif, walaupun akan menimbulkan polusi lingkungan yang cukup mengganggu.

Tidak semua orang tahu bahwasanya sampah daun dan bunga yang masih basah dapat dijadikan sebagai hasil kerajinan yang bernilai jual. Hiasan rumah yang cantik tidak harus selalu dibeli dengan harga yang mahal. Dengan memanfaatkan benda-benda di sekitar rumah untuk diubah menjadi sesuatu yang unik. Salah satunya adalah dedaunan dan bunga. Teknik ecoprinting, dedaunan atau bebungaan yang tumbuh di pekarangan rumah bisa jadi pengganti cairan kimia. Ecoprinting adalah satu cara menghias kain dengan memanfaatkan berbagai tumbuhan dengan memanfaatkan warna-warna alaminya (Kharishma \& Septiana, 2019).

Ecoprinting adalah teknik cetak yang memanfaatkan pewarna alami. Ecoprint merupakan salah satu teknik pewarnaan kain yang saat ini sedang tren di kalangan pelaku usaha busana dan pengrajin tekstil (Irmayanti et al., 2020). Dengan teknik ini, prosesnya sederhana dan tidak melibatkan mesin atau cairan kimia. Untuk membuat hiasan atau fashion yang ramah lingkungan, ecoprinting adalah jawabannya. Teknik ecoprinting biasa diaplikasikan pada bahan berserat alami seperti kain kanvas atau katun yang mampu menyerap warna dengan baik. Terdapat beberapa teknik ecoprinting yang biasa dipakai yaitu dengan menata daun atau bunga pada selembar kain kemudian menggulungnya di sekeliling batang kayu kemudian dikukus, memfermentasi daun dan bunga untuk mengekstrak pigmen warna yang ada di dalam tanaman tersebut dan yang paling sederhana yaitu memukulkan daun atau bunga ke atas kain menggunakan palu (Pressinawangi \& Dr.Dian Widiawati, 2014).

Dampak limbah cair industri tekstil terhadap lingkungan dan aplikasi teknik ecoprinting sebagai usaha mengurangi limbah. Industri tekstil di 
107 Pemanfaatan Sampah Daun dan Bunga Basah menjadi Kerajinan Ecoprinting - Rezkiyana Hikmah, Ria Asep Sumarni

DOI: https://doi.org/10.31004/abdidas.v2i1.225

Indonesia semakin bertambah seiiring dengan permintaan beragam produk tekstil yang selalu mengikuti tren mode, dan dalam pengolahannya selalu menghasilkan limbah berupa zat cair yang dapat mencemari sungai dan perairan di Indonesia. Salah satunya adalah dengan teknik ecoprinting dengan menggunakan zat pewarna alami. Dengan menggunakan eksplorasi teknik tersebut, juga diharapkan meningkatkan nilai jual dan kreativitas dari produk tekstil di Indonesia (Enrico, 2019).

Berdasarkan data hasil wawancara dengan ketua RT Perumahan Pamulang Park Residence yaitu Bapak Amin Mustaqim, warga memiliki permasalahan dalam kebersihan lingkungan dan pemanfaatan sampah daun-daun serta bunga yang masih basah. Banyaknya potensi alam di lingkungan sekitar dan masih minimnya kemampuan kelompok masyarakat dalam menghasilkan produk ecoprint (Saptutyningsih \& Titis, 2019). Oleh karena itu, berdasarkan permasalahan faktor kebersihan lingkungan dan pemanfaatan sumber daya alam, maka kami akan melakukan pengabdian masyarakat berupa sosialisasi pembuatan dan pemanfaatan sampah daun, serta bunga yang masih basah sebagai bahan pembuatan ecoprinting di lingkungan Perumahan Pamulang Park Residence khususnya Ibu-ibu PKK.

Berdasarkan permasalahan yang langsung ditinjau oleh tim pengabdian masyarakat di lingkungan Perumahan Pamulang Park Residence dapat disimpulkan bahwa:
1. Kebersihan lingkungan yang kurang terjaga, karena jarangnya kehadiran petugas kebersihan lingkungan perumahan untuk menyapu, sehingga daun-daun dan bunga yang berguguran banyak yang berserakan di jalan dan taman.

2. Kurangnya pengetahuan warga untuk memanfaatkan sumber daya alam seperti daun-daun dan bunga yang berguguran di lingkungan perumahan, sehingga warga kurang berinisiatif untuk memanfaatkan lebih lanjut sampah yang ada di lingkungan.

3. Warga belum ada yang bisa membuat ecoprinting dengan memanfaatkan daundaun dan bunga.

Adapun tujuan dari kegiatan pengabdian masyarakat kami, yaitu memperkenalkan dan mensosialisasikan pembuatan dan pemanfaatan daun-daun dan bunga yang berguguran di lingkungan perumahan sebagai bahan kerajinan ecoprinting yang lebih ramah lingkungan.

Solusi yang kami tawarkan dalam kegiatan pengabdian masyarakat kali ini, yaitu mengajak Ibu-ibu PKK untuk lebih ramah lingkungan dengan memanfaatkan daun-daun dan bunga yang berguguran sebagai bahan membuat kerajinan ecoprinting yang ramah lingkungan dengan teknik pembuatan yang sangat mudah, sehingga mudah dipelajari oleh warga. Adapun alternatif untuk memecahkan permasalahan mitra yang telah ada dapat dilihat pada tabel 1 . 
108 Pemanfaatan Sampah Daun dan Bunga Basah menjadi Kerajinan Ecoprinting - Rezkiyana Hikmah, Ria Asep Sumarni

DOI: https://doi.org/10.31004/abdidas.v2i1.225

Tabel 1. Alternatif Pemecahan Masalah

\begin{tabular}{|l|l|l|}
\hline No & Permasalahan & Alternatif Pemecahan Masalah \\
\hline 1 & $\begin{array}{l}\text { Kebersihan lingkungan yang kurang terjaga, karena } \\
\text { jarangnya kehadiran petugas kebersihan lingkungan } \\
\text { perumahan untuk menyapu, sehingga daun-daun dan } \\
\text { bunga banyak yang berserakan di jalan dan taman. }\end{array}$ & $\begin{array}{l}\text { Mengajak Ibu-ibu PKK di lingkungan sekitar } \\
\text { unt melakukan kegiatan kerja bakti bersih- } \\
\text { bersih lingkungan dengan menyapu daun-daun } \\
\text { dan bunga yang berguguran secara rutin, lalu } \\
\text { meletakkan daun-daun dan bunga tersebut di bak } \\
\text { khusus untuk persediaan bahan baku pembuatan } \\
\text { membuat kerajinan ecoprinting yang ramah } \\
\text { lingkungan dengan teknik pembuatan yang sangat } \\
\text { mudah. }\end{array}$ \\
\hline 2 & $\begin{array}{l}\text { Kurangnya pengetahuan warga untuk memanfaatkan } \\
\text { sumber daya alam seperti daun-daun dan bunga yang } \\
\text { berguguran di lingkungan perumahan, sehingga warga } \\
\text { kurang berinisiatif untuk memanfaatkan lebih lanjut } \\
\text { sampah yang ada di lingkungan. }\end{array}$ & $\begin{array}{l}\text { Memberikan sosialisasi manfaat kerajinan } \\
\text { ecoprinting berbahan daun-daun dan bunga } \\
\text { kepada warga lingkungan perumahan Pamulang } \\
\text { dan memberitahukan juga manfaat ekonomis yang } \\
\text { diperoleh dari mendaur ulang daun-daun dan } \\
\text { bunga menjadi kerajinan ecoprinting yang ramah } \\
\text { lingkungan dengan teknik pembuatan yang sangat } \\
\text { mudah. }\end{array}$ \\
\hline 3 & $\begin{array}{l}\text { Warga belum ada yang bisa membuat membuat kerajinan } \\
\text { ecoprinting berbahan dasar daun-daun dan bunga, } \\
\text { sehingga bisa dijadikan kerajinan tangan yang lebih } \\
\text { bermanfaat. }\end{array}$ & $\begin{array}{l}\text { Memberikan pelatihan pembuatan kerajinan } \\
\text { ecoprinting berbahan dasar daun-daun dan bunga } \\
\text { dengan menyediakan alat-alat dan bahan-bahan } \\
\text { yang dibutuhkan, seperti kain polos, alat pemukul, } \\
\text { dan alat bahan yang dibutukan lainnya. }\end{array}$ \\
\hline
\end{tabular}

Target pelaksanaan kegiatan pengabdian masyarakat ini, yaitu Ibu-ibu PKK Perumahan Pamulang Park Residence. Dengan target capaian, Ibu-ibu PKK perumahan Pamulang dapat memiliki tambahan pengetahuan dalam pembuatan kerajinan ecoprinting berbahan dasar daun-daun dan bunga yang sudah berguguran, serta mengajak warga untuk lebih ramah lingkungan, minimal dengan sering membersihkan lingkungan taman rumahnya masing-masing dan bekerja sama dengan PKK dalam memanfaatkan sampah daun-daun dan bunga untuk dibuat kerajinan ecoprinting, bukan dengan membakarnya.

\section{METODE}

Kegiatan ini dilaksanakan di komplek Perumahan PPR, yang beralamat di Jl. Surya Kencana, Kemuning V, RT/RW: 007/06, Pamulang Barat, Tangerang Selatan. Kegiatan ini dilaksanakan pada bulan Oktober 2019 - Februari 2020. Sasaran dari kegiatan ini adalah Ibu-ibu PKK di Perumahan Pamulang Park Residence.

Metode yang digunakan untuk mencapai tujuan yang dirumuskan tersebut adalah metode pelatihan dan pendampingan serta diskusi. Pelatihan dilakukan dengan cara memperkenalkan dan mensosialisasikan pembuatan dan pemanfaatan daun-daun dan bunga di lingkungan perumahan sebagai bahan dalam pembuatan ecoprinting yang lebih ramah lingkungan. Mengajak dan mengadakan pelatihan agar semakin meningkatnya kapasitas masyarakat dalam membuat ecoprint, sehingga dapat semakin berkembang pula motif atau metode lain yang juga layak dijual sehingga dapat meningkatkan kesejahteraan masyarakat (Sifaunajah \& Tulusiawati, 2020). Materi yang diberikan saat pelatihan meliputi langkah pembuatan dan 
109 Pemanfaatan Sampah Daun dan Bunga Basah menjadi Kerajinan Ecoprinting - Rezkiyana Hikmah, Ria Asep Sumarni

DOI: https://doi.org/10.31004/abdidas.v2i1.225

pemanfaatan daun-daun dan bunga sebagai pewarna alami dalam pembuatan kerajinan ecoprinting. Selain itu tanaman lain seperi jarak kepyar, kersen, mahoni, dan ketapang yang dapat di-ecoprint pada bahan fashion juga mudah ditemukan diberbagai tempat (Anang Setiyo Waluyo et al., 2019).

Pelaksanaan kegiatan ini dilakukan dalam tiga tahap, yaitu tahap persiapan, pelaksanaan, dan evaluasi.

1. Tahap pertama adalah tahap persiapan. Dalam tahap ini tim melakukan survei pendahuluan untuk mengetahui kondisi tempat kegiatan dengan menganalisis kondisi tempat yang akan digunakan, kondisi warga yang akan diberikan pelatihan, dan menyusun rancangan kegiatan yang akan dilakukan.

2. Tahap kedua yaitu tahap pelaksanaan. Tim melakukan pelatihan pembuatan ecoprinting yang ditujukan untuk Ibu-ibu PKK Pamulang Park Residence. Kegiatan pelatihan ini dilakukan agar warga bisa membuat ecoprinting untuk memanfaatkan sampah daun dan bunga yang berguguran di lingkungan sekitar. Adapun langkahlangkah pembuatan ecoprinting, yaitu:

3. Tahap ketiga adalah evaluasi. Evaluasi kegiatan ini dilakukan terhadap proses kegiatan. Evaluasi berkaitan selama kegiatan berlangsung dari tahap persiapan sampai tahap pelaksanaan, yang meliputi keadaan komplek, kehadiran peserta pelatihan, antusias peserta saat mengikuti kegiatan, dan saran atau kritik terhadap kegiatan.

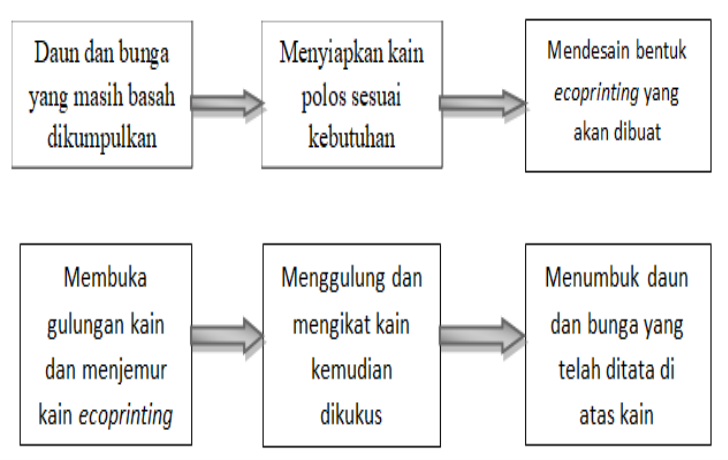

Gambar 1. Alur Pembuatan Ecoprinting

\section{HASIL DAN PEMBAHASAN}

\section{Tahap Persiapan}

Pada tahap ini tim melakukan survei pendahuluan untuk mengetahui kondisi tempat kegiatan dengan menganalisis kondisi tempat yang akan digunakan, kondisi warga yang akan diberikan pelatihan, dan menyusun rancangan kegiatan yang akan dilakukan. Sebelum pelaksanaan kegiatan, tim menyiapkan persiapan seperti alat dan bahan. Alat dan bahan yang diperlukan dalam kegiatan ecoprinting ini antara lain adalah: kain putih polos, gunting, penggaris, alat pemuluk (palu), papan tatakan/ talenan, baskom, air, tawas, cuka, dan berbagai jenis daun atau bunga basah.

\section{Tahap Pelaksanaan}

Tahap selanjutnya adalah tahap pelaksanaan. Pada tahap ini tim melakukan pelatihan kepada Ibu-ibu PKK dalam melakukan ecoprinting menggunakan sampah daun yang masih basah. Peserta pelatihan yang hadir berjumlah 15 orang.

Proses kegiatan ecoprinting yang dilaksanakan tersebut dimulai dengan menentukan bunga dan dedaunan yang akan dijadikan sebagai motif dan warna pada kain. Kain yang digunakan 
110 Pemanfaatan Sampah Daun dan Bunga Basah menjadi Kerajinan Ecoprinting - Rezkiyana Hikmah, Ria Asep Sumarni

DOI: https://doi.org/10.31004/abdidas.v2i1.225

adalah kain katun berwarna putih atau jenis kain yang memiliki daya serap yang maksimal. Selanjutnya daun dan bunga tersebut dibersihkan dan direndam dengan air cuka selama 15 menit. Hal ini untuk menghasilkan warna dan motif yang bagus pada kain katun. Motif merupakan inspirasi dari berbagai bentuk atau objek yang dituangkan dalam bentuk 2 dimensi (Ikhsani \& Yulistiana, 2020). Kemudian daun tersebut diangkat dan dikeringkan di atas tisu atau kain kering.

Selanjutnya, menyiapkan kain katun berwarna putih dan menata dedaunan tersebut pada setengah kain tersebut. Setengah kain lainnya digunakan untuk menutupi daun yang sudah ditata. Selanjutnya, daun yang telah ditutup dengan sebagian kain tersebut akan dipukul dengan palu sehingga akan mengeluarkan warna dan motif unik yang indah pada kain. Teknik ini menggunakan suatu benda yang keras atau berat dengan menggunakan kekuatan untuk memunculkan sumber warna yang ada pada tumbuhan (Afiddah \& Murwandani, 2021). Setelah semua motif sudah terlihat sempurna pada kain, langkah berikutnya adalah membersihkan sisa daun yang menempel pada kain dan merendam kain tersebut dengan air tawas selama 30 menit. Hal tersebut berguna agar warna dan motif yang sudah ada pada kain dapat menyerap pada kain dengan sempurna dan motif pada kain tidak mudah luntur.

Kegiatan ini dimulai oleh dengan memberikan penjelasan secara lisan oleh salah tim mengenai apa itu ecoprinting dan manfaatnya. Selanjutnya, tim memperlihatkan bahan dan alat yang diperlukan beserta kegunaannya masingmasing. Kemudian salah satu tim mendemonstrasikan bagaimana proses membuat kain batik dengan proses ecoprinting tersebut kepada peserta. Pada awal proses demonstrasi tersebut, tim sudah menjelaskan kepada peserta bahwa kegiatan demonstrasi ecoprinting tersebut akan diikuti oleh kegiatan eksperimen langsung dari peserta yang hadir. Selama proses demonstrasi tersebut, tim dan peserta melakukan interaksi berupa tanya jawab seputar tahap dan proses membuat kain batik dengan ecoprinting tersebut, sehingga kegiatan dalam mendemonstrasikan proses ecoprinting memunculkan keakraban antara tim dengan para peserta dan terjalinnya komunikatif yang baik dengan para peserta. Kegiatan membuat kain batik pun menjadi hal yang seru dan antusias bagi peserta dan tim abdimas.

Pada proses demo tersebut, tim membagi peserta menjadi 3 kelompok. Setiap kelompok diberi alat dan bahan ecoprinting. Hal tersebut dilakukan agar peserta dapat mengikuti langkah demonstrasi proses ecoprinting pada kelompok masing-masing sehingga peserta diberikan pengalaman langsung dalam bereksperimen ecoprinting. Setiap kelompok bekerja sama dengan masing-masing anggota kelompoknya dalam mencoba proses ecoprinting tersebut. Hal tersebut terlihat pada saat peserta menata dedaunan di atas kain. Setiap peserta ikut memberikan saran dan mencoba untuk menata dedaunan tersebut dengan solid sedemikian sehingga terlihat rapi dan indah. Selanjutnya menutup sebagian kain yang tersisa di atas dedaunan yang sudah tertata rapi tersebut untuk siap dipukul dengan palu. kegiatan memukul daun tersebut pun tidak sembarang. 
111 Pemanfaatan Sampah Daun dan Bunga Basah menjadi Kerajinan Ecoprinting - Rezkiyana Hikmah, Ria Asep Sumarni

DOI: https://doi.org/10.31004/abdidas.v2i1.225

Peserta memukul daun tersebut dengan memperhatikan serat dan lekukan serta permukaan daun agar motif daun terbentuk dengan sempurna. Peserta pun melakukannya dengan antusias secara bergantian mencoba pengalaman tersebut. Selanjutnya membersihkan kain tersebut dari dedaunan yang menempel dan merendam kain tersebut dengan air tawas selama 30 menit. Setelah 30 menit, kain tersebut dikeringkan dan para peserta terlihat begitu senang saat melihat hasil karya kain batik ecoprinting yang sudah mereka kerjakan. Setiap kelompok memperlihatkan hasil karya kain batik ecoprinting kepada para peserta kelompok lainnya. Kegiatan tersebut juga didampingi oleh 2 mahasiswa Informatika sebagai pengalaman dalam melaksanakan kegiatan pengabdian kepada masyarakat.
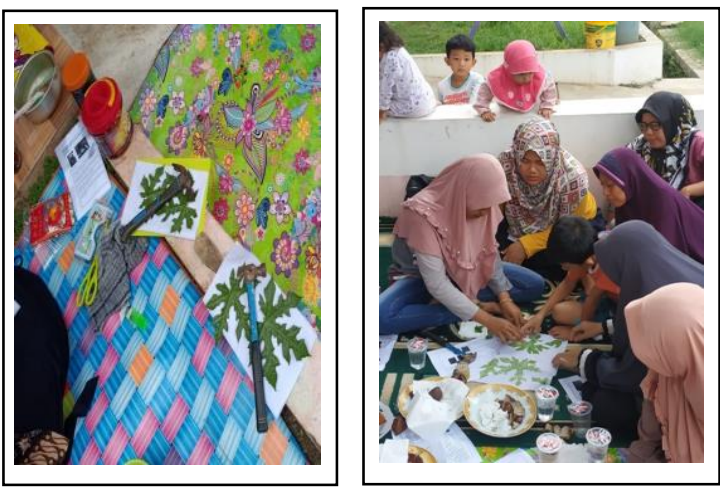

Gambar 2. Pelatihan Ecoprinting

Kegiatan pengabdian masyarakat yang telah dilaksanakan secara keseluruhan berjalan dengan lancar dan sukses. Walaupun ada peserta yang datang terlambat pada proses demonstrasi ecoprinting. Tim segera mengajak peserta tersebut untuk bergabung dengan salah satu kelompok agar ikut berpartisipasi pada saat proses tahap memukul dedaunan pada kain. Tim juga menjelaskan kembali proses dari ecoprinting sebagai bentuk solusi dari ketidaktahuan peserta tersebut dengan apa itu ecoprinting, manfaat dan proses cara membuat kain batik dengan ecoprinting.

\section{Tahap Evaluasi}

Pada tahap terakhir kegiatan ini adalah evaluasi, tim kembali membuka sesi tanya jawab dan diskusi, untuk mengetahui kemampuan dari peserta. Saat sesi ini, ada beberapa peserta yang bertanya mengenai teknik dan jenis-jenis daun yang tepat untuk ecoprinting. Tim kembali menjelaskan teknik dan jenis-jenis tanaman yang baik untuk digunakan dalam teknik ecoprinting. Tanaman yang baik untuk dijadikan bahan dalam ecoprinting adalah tanaman yang mengandung zat warna kuat agar menghasilkan warna yang bagus.

Dampak dari hasil pelatihan membuat kain ecoprinting adalah sikap antusias dan kreatif peserta dalam menentukan jenis dedaunan dan bunga yang akan dijadikan motif unik dan menatanya sedemikian teratur dan indah pada kain. Selain itu, kegiatan ecoprinting ini juga menjadikan alternatif ide bisnis bagi para peserta yang pada umumnya adalah ibu rumah tangga. Usaha-usaha untuk membudiyakan tanaman, hewan dan ikan yang ada di sekitar kita dengan menggunakan sarana sendiri maupun untuk di pasarkan (Yulia, 2021). Bisnis ini memiliki pasar yang cukup bagus karena motif dan warna kain yang dihasilkan dari proses ecoprinting begitu unik. Hal ini dikarenakan proses ecoprinting membutuhkan waktu yang cukup lama dalam memilih dedaunan dan bunga yang akan digunakan serta dalam menatanya pada kain yang berukuran 
112 Pemanfaatan Sampah Daun dan Bunga Basah menjadi Kerajinan Ecoprinting - Rezkiyana Hikmah, Ria Asep Sumarni

DOI: https://doi.org/10.31004/abdidas.v2i1.225

lebih panjang. Oleh karena itu, nilai jual dari kain hasil ecoprinting ini termasuk dalam kategori mahal.

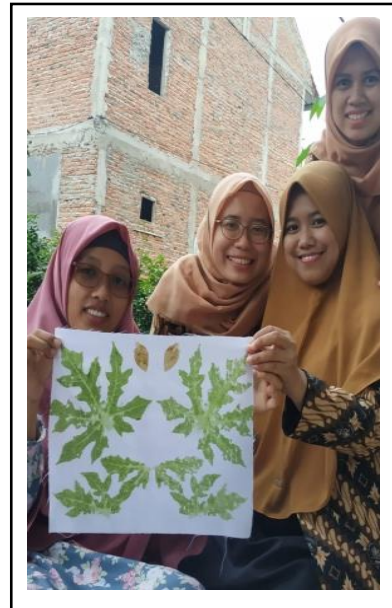

Gambar 3. Hasil Pelatihan Ecoprinting

Hasil kain ecoprinting yang mereka buat dapat dijadikan sebagai barang-barang yang bernilai seperti pakaian batik (baju maupun rok), totobag dan aneka barang lainnya. Hal ini dikarenakan motif dari hasil ecoprinting pada kain sangat unik dan proses membuatnya pun butuh waktu yang cukup lama untuk membuat kain ecoprinting dengan ukuran yang lebih besar. Selain itu, dedaunan yang digunakan dapat beragam untuk menghasilkan motif dan corak warna yang unik dan indah.

Di penghujung acara dilakukan sesi foto bersama antara Tim abdimas dengan peserta pelatihan sebagai dokumnetasi kegiatan. Kegiatan ini juga dapat dijadikan sebagai salah satu alternatif penanggulangan sampah daun dan bunga basah yang selama ini hanya menjadi sampah dapat diolah menjadi aneka barang yang bermanfaat dan memiliki nilai dijual. Hasil kain ecoprinting bisa dijadikan sebagai fashion atau kerajinan lain yang dapat membuka lapangan usaha.

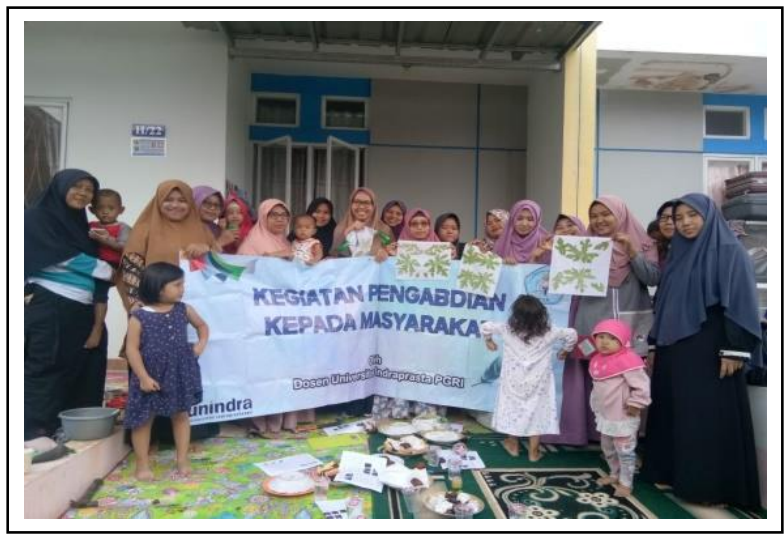

Gambar 4. Foto Bersama di Akhir Kegiatan

\section{SIMPULAN}

Dari hasil kegiatan ini menjadikan Ibu-Ibu PKK di Perumahan Pamulang Park Residence memiliki ketrampilan dalam membuat ecoprinting, yang hasilnya dapat mereka aplikasikan dalam membuat suatu bentuk kerajinan, salah satunya totebag. Selain itu, kegiatan ini juga memberikan wawasan kepada warga untuk lebih menjaga lingkungan agar tidak membakar sampah.

\section{UCAPAN TERIMAKASIH}

Penulis mengucapkan terimakasih kepada Lembaga Penelitian dan Pengabdian Kepada Masyarakat Universitas Indraprasta PGRI Jakarta yang memberikan kesempatan untuk melaksanakan salah satu Tri Dharma Perguruan Tinggi yakni pengabdian kepada masyarakat, kepada Ketua RT dan Ibu-ibu PKK di Perumahan Pamulang Park Residence atas kesediaannya sebagai tempat, serta semua pihak yang telah berpartisipasi dalam kegiatan ini. 
113 Pemanfaatan Sampah Daun dan Bunga Basah menjadi Kerajinan Ecoprinting - Rezkiyana Hikmah, Ria Asep Sumarni

DOI: https://doi.org/10.31004/abdidas.v2i1.225

\section{DAFTAR PUSTAKA}

Afiddah, A. S., \& Murwandani, N. G. M. (2021). Penerapan Teknik Ecoprint Pada Produk Non Bahan Sandang. Jurnal Seni Rupa, 9(2), 220231.

Anang Setiyo Waluyo, L., Agustini Srimulyani, V., \& Rustiyaningsih, S. (2019). PKM Kerajinan Batik Ecoprint Dan Tie Dye Di Kota Madiun Dan Ponorogo. ASAWIKA: Media Sosialisasi Abdimas Widya Karya, 4(02), 6-10. https://doi.org/10.37832/asawika.v4i02.4

Enrico. (2019). Dampak Limbah Cair Industri Tekstil Terhadap Lingkungan dan Aplikasi Tehnik Eco Printing sebagai Usaha Mengurangi Limbah. Moda, 1(1), 5-13.

Ikhsani, N., \& Yulistiana. (2020). Penerapan Desain Motif Bunga Pada Scarf Menggunakan Teknik Eco Printing. Jurnal Tata Busana, 9(2), 57-64.

Irmayanti, Suryani, H., \& Megavitry, R. (2020). Pemanfaatan Bahan Alami Untuk Pembuatan Ecoprint Pada Peserta Kursus Menjahit Yayasan Pendidikan Adhiputeri Kota Makassar. Jurnal Hasil Pengabdian Masyarakat, 1(1), 43-50.

Kharishma, V., \& Septiana, U. (2019). Pelatihan Teknik Ecoprint untuk Guru PAUD. Seminar Nasional: Seni, Teknologi Dan Masyarakat, 2, 183-187.

Pohan, Y. F., \& Supriharjo, R. D. (2013). Pengelolaan Sampah Perumahan Kawasan Pedesaan Berdasarkan Karakteristik Timbulan. Jurnal Teknik Pomits, 2(1), C37C42.

Pressinawangi, R. N., \& Dr.Dian Widiawati, M. S. (2014). Eksplorasi Teknik Ecoprint Dengan Menggunakan Limbah Besi Dan Pewarna Alami Untuk Produk Fashion. Jurnal Tingkat Sarjana Bidang Senirupa Dan Desain, 3(1), $1-7$.

Saptutyningsih, E., \& Titis, D. (2019). Pemanfaat Bahan Alam Untuk Pengembangan Produk. Warta LPM, 22(1), 18-26.

Sifaunajah, A., \& Tulusiawati, C. (2020). Pengembangan Kerajinan Batik dengan Teknik Ecoprint bersama Organisasi Karang
Taruna dan IPNU-IPPNU Desa Barongsawahan. Jurnal Pengabdian Masyarakat Bidang Keagamaan, 1(1).

Taufiq, A., \& Maulana, F. M. (2015). Sosialisasi Sampah Organik Dan Non Organik Serta Pelatihan Kreasi Sampah. Jurnal Inovasi Dan Kewirausahaan, 4(1), 68-73.

Yulia. (2021). Pendampingan Analisis Usaha Pembuatan Abon Rebung di UKM "Raja Abon Makmur Lestari" Kelurahan Air Kepala Tujuh Kota Pangkal Pinang. Jurnal Abdidas, 2(1), 59-68. 